\title{
(2) OPEN ACCESS \\ Acute psychosis in glycogen storage disease: a rare but severe complication
}

\author{
Thomas Frederick Dunne, ${ }^{1}$ Tarekegn Geberhiwot, ${ }^{2}$ Rowena Jones ${ }^{3}$
}

${ }^{1}$ College of Medical and Dental Sciences, University of Birmingham, Birmingham, UK ${ }^{2}$ Institute of Metabolism and Systems Research, University of Blrmingham, Birmingham, UK ${ }^{3}$ Department of Psychiatry, Queen Elizabeth Hospital, Birmingham, UK

\section{Correspondence to} Dr Tarekegn Geberhiwot, Tarekegn.Geberhiwot@uhb. bhs.uk

Accepted 12 February 2019

Check for updates

(c) BMJ Publishing Group Limited 2019. Re-use permitted under CC BY-NC. No commercial re-use. See rights and permissions. Published by BMJ.

To cite: Dunne TF, Geberhiwot T, Jones R. BMJ Case Rep 2019:12:e222307. doi:10.1136/bcr-2017222307

\section{SUMMARY}

Glycogen storage disease type 1 (GSD-1) is a group of inherited metabolic disorders characterised by the inability to use intracellular glucose stores. It is associated with a high risk of hypoglycaemia, as well as long-term complications including growth retardation, hepatocellular adenomas, renal disease, hypertriglyceridaemia and hyperuricaemia. Treatment involves slow absorption carbohydrates, for example, cornstarch. We present a case of acute psychosis in a patient with GSD-1a. This was initially attributed to his opiate use. Later in his management an MRI scan of his head was performed which revealed regions of brain atrophy following significant hypoglycaemic insult, thus identifying an organic cause of his psychosis. This case presents a rare complication of glycogen storage disease: organic psychosis attributable to cortical atrophy from profound hypoglycaemic insult. It emphasises the importance of investigating organic causes of psychiatric symptoms.

\section{BACKGROUND}

Glycogen storage disease type 1 (GSD-1), or glucose-6-phosphatase deficiency, is characterised by the inability to hydrolyse glucose-6-phosphate in the pathway of glycogen breakdown for intracellular utilisation. ${ }^{1}$ It is one of a group of glycogen storage diseases, characterised by defects in glycogen metabolism. GSD-1 has two further subtypes based on the affected gene, $1 \mathrm{a}$ and $1 \mathrm{~b}$, which have overlapping clinical symptoms. ${ }^{1}{ }^{2}$ Incidence of the disease is thought to be around 1 in 100000 births worldwide. ${ }^{2}$ With an inability to use stored glucose, patients are at risk of hypoglycaemic insult when faced with a metabolic stressor or after a period of fasting. As such, the disease is often picked up at around $3-4$ months of age due to fasting-onset hypoglycaemia or lactic acidaemia. ${ }^{3}$ Common signs at presentation include hepatomegaly and the effects of hypoglycaemia, for example, cyanosis, apnoea and neuroglycopenic symptoms such as hypotonia, seizures and coma. ${ }^{2-4}$ This clinical presentation is key to diagnosis and can be aided with biochemical testing, genetic testing and liver biopsy enzymology. ${ }^{5}$

The long-term complications of GSD-1 deficiency include growth retardation, development of hepatocellular adenomas, ${ }^{3}$ renal disease, hypertriglyceridaemia, ${ }^{6}$ hyperuricaemia ${ }^{7}$ and pulmonary hypertension. ${ }^{89}$ Good glycaemic control minimises the risk of developing these complications and so treatment focuses on preventing hypoglycaemic insult through dietary interventions. ${ }^{3} 410$ Such treatments include frequent nutritional intake with the addition of slow-absorption carbohydrates. ${ }^{11}$ It is recommended that carbohydrates provide $60 \%-70 \%$ of dietary intake, with their ingestion being evenly distributed over a 24 hours period. ${ }^{5}$ Cornstarch is most commonly prescribed, with dosage based on a patient's weight. ${ }^{12}$ The American College of Medical Genetics and Genomics suggest a young child consume $1.6 \mathrm{~g} / \mathrm{kg}$ of cornstarch three to four times an hour, while older children and adults consume $1.7-2.5 \mathrm{~g} / \mathrm{kg}$ four to five times an hour. In adulthood a single evening dose can be sufficient to maintain a healthy blood glucose throughout the night. ${ }^{5}$ If normoglycaemia is achieved, morbidity and mortality can be significantly decreased. ${ }^{3} 13$ Otherwise, further complications of long-term hypoglycaemia and its consequences can manifest. There is still debate regarding whether early management and good metabolic control can prevent all long-term complications e.g. hepatic adenomas. ${ }^{2}$ Amylase is required for cornstarch digestion which may not be produced in sufficient quantities until 2 years of age. It is suggested that a small dose of corn starch be started in infancy and then titrated up to the target $1.6 \mathrm{~g} / \mathrm{kg}$ three to four times an hour to improve tolerance. ${ }^{5}$

This is the first documented case of acute psychosis attributable to profound hypoglycaemia in GSD-1. It highlights a rare complication of the illness and is relevant to other conditions with an associated risk of severe hypoglycaemic insult. This case also illustrates the importance of exploring organic causes of psychiatric symptoms and considering alternative diagnoses where a working diagnosis does not fully explain the clinical picture.

\section{CASE PRESENTATION}

A man aged 33 years with a history of GSD-1a was admitted to the emergency department with a 5-day history of acute psychosis. He reported persecutory delusions and visual hallucinations, and exhibited violent behaviour including throwing objects and banging his head. His past medical history included chronic viral hepatitis, diabetes mellitus, chronic pain, opiate dependence, and complications of GSD-1a including pancreatic insufficiency; hepatic adenomas; inflammatory bowel disease and suboptimal metabolic control with recurrent hypoglycaemia. He had no previous psychiatric history or family history of psychiatric illness. 
He was diagnosed with GSD-1a at 4 months of age following hypoglycaemic encephalopathy. Diagnosis was based on a clinical picture of severe hypoglycaemia and confirmed with liver enzyme analysis. He started taking treatment with frequent small feeding and cornstarch 30-90g/day. Adequate treatment continued throughout his childhood but difficulties with compliance arose during his teenage years, continuing into adulthood. A recent 7-day continuous blood glucose monitor reported glycaemia averaging suboptimal, with peak hypoglycaemia at $1.9 \mathrm{mmol} / \mathrm{L}$. Due to the chronicity of this hypoglycaemia, the patient has started to show signs of compensation including raised lactate, once reported to be as high as $14.5 \mathrm{mmol} / \mathrm{L}$. In addition to this, the neuroglycopenic symptoms previously experienced when he would become hypoglycaemic are no longer exhibited, putting him at significant risk of severe hypoglycaemia. As a result of this he has had multiple hospital admissions with symptoms such as confusion, seizures and loss of consciousness.

He lives with his parents and has one sibling, a brother, also with GSD-1a (who has fewer complications due to better treatment compliance). The patient holds a university degree and was previously able to work. He was reviewed by the liaison psychiatry team who did not identify an organic cause for the behaviour. He was given a working diagnosis of psychosis secondary to opiate use for his chronic abdominal pain. He was admitted to an inpatient psychiatric unit due to symptom severity and treated with olanzapine and procyclidine.

\section{INVESTIGATIONS}

Fourteen months after the diagnosis of psychosis secondary to opiate dependence, persistent visual hallucinations prompted his psychiatrist to request an MRI scan of his head. Visual hallucinations are common in organic psychiatric illness and their persistence following resolution of the patient's delusions suggested that organic illness should be considered. ${ }^{14}$ Furthermore, hypoglycaemic insult is a known cause of brain injury. ${ }^{15} 16$ The MRI showed marked frontoparietal cortical atrophy, an organic brain injury that could explain the psychotic symptoms. ${ }^{17} 18$ This scan was compared with a previous MRI scan performed during a hospital admission for seizures, prior to the onset of psychotic symptoms. The earlier scan also showed evidence of frontoparietal cortical atrophy, however there was marked progression of atrophy between the two.

\section{DIFFERENTIAL DIAGNOSIS}

At the presentation of acute psychosis, a diagnosis of psychosis secondary to opiate use was given, based on his history of opiate dependence. However, subsequent review of investigations performed before and after the onset of psychotic symptoms suggested an organic cause. The marked progression of cortical atrophy between the two MRI scans showed that onset of psychotic symptoms followed a period of brain injury. An organic cause is also favoured by the clinical picture; visual hallucinations were the dominant and persisting symptom reported by the patient and these more frequently indicate organic brain disease. There is no family history of psychiatric illness and family history is often a feature of non-organic psychiatric illness. He does however, continue to lack insight into his symptoms which is less in keeping with organic disease.

There are two main candidate organic psychotic disorders which would fit with his symptoms. Psychotic disorder with hallucinations due to known physiological condition (F06.0), previously called organic hallucinosis, is one possible organic cause. This diagnosis allows lack of insight into hallucinations and gives some explanation for delusions. This is a less favourable diagnosis here as the condition usually characterised by hallucinations and delusions are not prominent. Alternatively, organic (schizophrenia-like) delusional disorder (F06.2) predominantly characterised by delusions though hallucination may also be present. This patient's symptoms appear to span the two diagnoses.

Functional psychosis—schizophrenia (F20)—was also considered as a diagnosis. When the patient first became unwell and needed to be admitted to a psychiatric unit he had prominent delusions as well as auditory and visual hallucinations. The presenting symptoms could also be explained by a mixed functional and organic illness. Conditions like schizophrenia are often explained by a stress vulnerability model. The patient may have had a predisposition to psychosis (perhaps related to the psychological burden of having a chronic debilitating disease), and the brain injury could have triggered its onset. ${ }^{19}$

\section{TREATMENT}

This patient remains on medications to treat his symptoms of psychosis, chronic pain and complications of GSD-1a. His routine medications include olanzapine $25 \mathrm{mg}$ once a day, amitriptyline $30 \mathrm{mg}$ once a day, fentanyl patch $12 \mathrm{mcg} /$ hour every 72 hours, glycoside 30-90 g/day, creon 25000 five times a day, levetiracetam $1000 \mathrm{mg}$ twice a day, sodium valproate $300 \mathrm{mg}$ twice a day, mesalazine $800 \mathrm{mg}$ three times a day, atorvastatin $20 \mathrm{mg}$ once a day, colecalciferol 800 units once a day and cyclizine $50 \mathrm{mg}$ once a day.

\section{OUTCOME AND FOLLOW-UP}

Since discharge from the unit, he has experienced chronic and intractable psychopathology. He continues to have persecutory delusions, though at a lower intensity since commencing antipsychotic therapy. He also experiences visual and nociceptive hallucinations, for example, seeing caterpillars on the ceiling at night that proceed to fall on to the bed and administer painful stings. His symptoms have resulted in ongoing antipsychotic therapy and requiring high levels of support from his community mental health team.

There are documented cases of brain injury attributable to hypoglycaemia. ${ }^{15} 16$ Due to the evidence of worsening injury over a period of time that psychiatric symptoms presented, the patient's symptoms were attributed to hypoglycaemia. The diagnosis of psychosis secondary to opiate use was therefore replaced with that of organic psychosis secondary to glycogen storage disease. This diagnosis is more in keeping with the initial presentation that is, visual and nociceptive modalities being more indicative of an organic psychosis than one of a psychological cause. It remains unclear whether the damage seen was caused by chronic hypoglycaemia, or an episode of severe hypoglycaemia, for example, hypoglycaemic coma.

\section{DISCUSSION}

We present the case of a patient with GSD-1a who attended the emergency department with acute psychosis following an episode of severe acute hypoglycaemia. A search strategy of 'hypoglycaemia' AND 'psychosis' was used with PubMed and found two previous cases of acute psychosis following hypoglycaemia. ${ }^{20}{ }^{21}$ These cases refer to acute hypoglycaemia, indicating the importance of checking blood glucose in patients presented with psychotic symptoms for the first time. To our knowledge, there are no documented cases of a patient presented with acute psychosis following a complex history of chronic hypoglycaemia. 
A wider search was conducted to investigate whether cases of brain injury secondary to hypoglycaemia had been reported in patients with other monogenic diseases associated with hypoglycaemia, for example, fructose-1,6-bisphosphatase deficiency and Medium-chain acyl-CoA dehydrogenase deficiency. A search using the terms 'hypoglycaemia' AND 'brain injury' located multiple articles reporting neurological insult in diabetes mellitus, neonatal hypoglycaemia and hypoglycaemic coma. No other case reports of brain injury in a patient with a monogenic condition predisposing to hypoglycaemia was found.

This case highlights a rare complication of GSD-1a and illustrates the importance of ruling out all organic causes of psychosis prior to diagnosing a primary psychotic disorder. Due to the rarity of this complication, it was not originally considered as an organic cause of the illness. In cases of patients with poorly managed GSD-1a presented with acute psychosis, head imaging should be considered to rule out cortical atrophy secondary to severe hypoglycaemia. Similarly, an acute psychosis in patients with other conditions that predispose to hypoglycaemia should prompt investigation for neurological insult.

\section{Learning points}

- Profound hypoglycaemia in glycogen storage disease type 1a can lead to cortical atrophy and resultant psychiatric illnessa rare but severe complication.

- Patients at risk of severe hypoglycaemia presented with psychotic symptoms should be considered for brain imaging.

- It is important to reconsider a diagnosis if it does not explain a patient's symptom profile.

Acknowledgements Many thanks are offered to the patient about whom this report is written for allowing their story to be used to educate others.

Contributors TFD: author of article. TG: corresponding author, patient's endocrinologist, editor of article. RJ: patient's psychiatrist, editor of article.

Funding This study was funded by UHB Charity.

Competing interests None declared.

Patient consent for publication Obtained.

Provenance and peer review Not commissioned; externally peer reviewed.

Open access This is an open access article distributed in accordance with the Creative Commons Attribution Non Commercial (CC BY-NC 4.0) license, which permits others to distribute, remix, adapt, build upon this work non-commercially, and license their derivative works on different terms, provided the original work is properly cited and the use is non-commercial. See: http://creativecommons.org/ licenses/by-nc/4.0/.

\section{REFERENCES}

1 Froissart R, Piraud M, Boudjemline AM, et al. Glucose-6-phosphatase deficiency. Orphanet J Rare Dis 2011;6:27.

2 Chen YT. Glycogen storage diseases. In: Scriver CR, Beaudet AL, Sly WS, eds. The Metabolic Bases of Inherited Disease. 8th edn. New-York: McGraw-Hill, 2000:1521-51.

3 Rake JP, Visser G, Labrune P, et al. Glycogen storage disease type I: diagnosis, management, clinical course and outcome. Results of the European Study on Glycogen Storage Disease Type I (ESGSD I). Eur J Pediatr 2002;161(Suppl.1):S20-34.

4 Smit GPA, Rake JP, Akman HO, et al. The Glycogen-Storage Diseases and Related Disorders "Liver glycogenoses". In: Fernandes J, Saudubray JM, van den Berghe G, eds. Inborn Metabolic Diseases. 4th edn. Heidelberg: Springer Medizin Verlag, 2006:p101-12

5 Kishnani PS, Austin SL, Abdenur JE, et al. Diagnosis and management of glycogen storage disease type I: a practice guideline of the American College of Medical Genetics and Genomics. Genet Med 2014;16:e1.

6 Kikuchi M, Hasegawa K, Handa I, et al. Chronic pancreatitis in a child with glycogen storage disease type 1. Eur J Pediatr 1991;150:852-3.

7 Cohen JL, Vinik A, Faller J, et al. Hyperuricemia in glycogen storage disease type I. Contributions by hypoglycemia and hyperglucagonemia to increased urate production. J Clin Invest 1985;75:251-7.

8 Humbert M, Labrune P, Sitbon 0, et al. Pulmonary arterial hypertension and type-I glycogen-storage disease: the serotonin hypothesis. Eur Respir J 2002;20:59-65.

9 Humbert M, Labrune P, Simonneau G. Severe pulmonary arterial hypertension in type 1 glycogen storage disease. Eur J Pediatr 2002;161(Suppl.1):S93-96.

10 Bali DS, Chen YT. Glycogen storage disease type I. In: Pagon RA, Bird TC, Dolan CR, eds. Genereviews. Seattle: University of Washington, 2008:1993-2006.

11 Weinstein DA, Wolfsdorf JI. Effect of continuous glucose therapy with uncooked cornstarch on the long-term clinical course of type 1a glycogen storage disease. Eur J Pediatr 2002;161(Suppl 1):S35-9.

12 Chen YT, Cornblath M, Sidbury JB. Cornstarch therapy in type I glycogen-storage disease. N Eng/ I Med 1984;310:171-5.

13 Däublin G, Schwahn B, Wendel U. Type I glycogen storage disease: favourable outcome on a strict management regimen avoiding increased lactate production during childhood and adolescence. Eur J Pediatr 2002;161(Suppl 1):S40-5.

14 Chaudhury S. Hallucinations: Clinical aspects and management. Ind Psychiatry J 2010;19:5-12.

15 Maheshwari M, Jain R. Hypoglycaemic brain injury: a case report. IJCP 2014:25:348-9.

16 Bal S, Goyal M, Smith E, et al. Chapter 21 - Central nervous system imaging in diabetic cerebrovascular diseases and white matter hyperintensities. In: Zochodne DW, Malik RA, eds. Handbook of Clinical Neurology. : Elsevier, 2014:126: 291-315.

17 Bonilha L, Molnar C, Horner MD, et al. Neurocognitive deficits and prefrontal cortical atrophy in patients with schizophrenia. Schizophr Res 2008;101(1-3):142-51.

18 Louhija UM, Saarela T, Juva K, et al. Brain atrophy is a frequent finding in elderly patients with first episode psychosis. Int Psychogeriatr 2017;29:1925-9.

19 World Health Organisation. International statistical classification of diseases and related health problems. 5th edn, 2016.

20 Padder T, Jaghab K. Gorman J. A 56-Year-Old Male Presenting with Acute Psychosis and Acute Change in Mental Status. I Psychiatr Pract 2006;12:411-4.

21 Singh SK, Agrawal JK, Srivastava AS, et al. Acute psychotic disorder and hypoglycemia. Indian J Psychiatry 1994:36:93-4.

Copyright 2020 BMJ Publishing Group. All rights reserved. For permission to reuse any of this content visit

https://www.bmj.com/company/products-services/rights-and-licensing/permissions/

BMJ Case Report Fellows may re-use this article for personal use and teaching without any further permission.

Become a Fellow of BMJ Case Reports today and you can:

- Submit as many cases as you like

- Enjoy fast sympathetic peer review and rapid publication of accepted articles

- Access all the published articles

Re-use any of the published material for personal use and teaching without further permission

Customer Service

If you have any further queries about your subscription, please contact our customer services team on +44 (0) 2071111105 or via email at support@bmj.com.

Visit casereports.bmj.com for more articles like this and to become a Fellow 